\title{
Presenting a Conceptual Model for Systematic Structure of Production in the Light of Various Structures of Supply Chain Network
}

Amir Parishani ${ }^{1}$

Hasan Akbari2

Hamed Jafar Zanjani3

${ }^{1}$ Department of Industrial Engineering,Naragh Branch, Islamic Azad University, ,Naragh, Iran 2Department of Industrial Engineering, Delijan Branch,Islamic Azad University, ,Delijan,Iran ${ }^{3}$ Department of Industrial Engineering,Naragh Branch,Islamic Azad University, ,Naragh,Iran

\section{Doi:10.5901/mjss.2016.v7n2s2p9}

\section{Abstract}

\begin{abstract}
The purpose of the present study is to provide a systematic conceptual model of the structure of the supply chain network. The study sample is agricultural sector selected by snowball sampling, 50 scholarship experts in the field of agriculture equipment were selected to collect data. Collecting data in this study is a combination of library and field methods. To determine the optimal pattern of production, including the Cobb-Douglas production function frequently, transcendental, secondarily generalized trans log by software SPSS, eviews5 was estimated and to determine the best function that can explain better structure the Durbin-Watson test for autocorrelation test, variance inflation test to check the alignment, Jrakbra test to check the normality of the disturbance terms Arch test for heterogeneity of variance was used. The results showed that there is a significant relationship between the inputs in the production process. Between the average costs and amount of production there is a significant relationship and between the systematic production and supply chain network structure there is a significant relationship.
\end{abstract}

Keywords: Systematic Structure of Production, Supply Chain, Agricultural Equipment

\section{Introduction}

In recent decades the economy has characteristics such as increased competition and internationalization of the production process is rapidly changing. In such circumstances, there are major competitive advantages in regional markets as the groups bilateral and interdependent world is evident. Undoubtedly, maintaining harmony and alignment with global and international developments in the industry and activity is necessary and important.

Supply Chain Management is a set of procedures to effectively integrate suppliers, manufacturers, warehouses and retailers applies to products required to produce a specified amount and on time and to customers to minimize the cost of the entire chain and also meet the needs of customers with high service level. (Patterson, 2000)

\section{Statement of the Problem}

The main and primary factor in determining the type of network providers is the number of organizations that have mastered network. In a division of the existing network of suppliers include: KINGDOM network; BARONY network; REPUBLIC network (Ghazanfari et al., 2001)

In this network KINGDOM, there are confrontation, confront and competition between different networks, while creativity at different levels of the supply network structure is specific to the network.

BARONY manifest when the position of the center of a network of several organizations devoted to it. One of the benefits Networks BARONY is bases providing common to all BARON is the result of innovation and creativity in technical created by suppliers to speed on all BARON emissions data that would lead to value creation Added to the network.

REPUBLIC network is emerged when central organization are not exist (the dominant power) in the network. First difference between REPUBLIC networks and KINGDOM and BARONY networks is the nature of their customers. In the network REPUBLIC, customers, companies that sell products to end users, while KINGDOM networks and BARONY, 
customers are the end users.

According to the structure of the industry in this industry if enterprises with a size or a certain production level has the lowest cost per unit of production and enterprises with a smaller size or larger than the first Group enterprises incur cost more per unit product, existence of a curve with this shape, which means that enterprises in the second group with a change in the size or scale of production and delivery unit size to the size of the firms in the first group, can reduce the production cost per unit and increase their competitiveness in the market. (Dashti and Shorafa, 2009)

The author tried to provide an appropriate model for systematic production under different structures chain network model.

\section{History of Research}

Jayaraman and Pirkul presented an integrated model of zero and a complex plan. In this model the objective function for at least the cost of the entire chain, which fixed the fee includes the cost of establishment, operations and warehouses, the variable cost of production and distribution of the cost of transportation of raw materials to production centers and then transport finished products to customers through warehouses. (Pirkul, Jayaraman. 1998) Another study looked at the model is PLANWAR. This model factories and warehouses resolve previous issues with placement, taking into account capacity constraints (Pirkul, Jayaraman, 2001)

Cohen and Moon with a mixed model of zero and an attempt to optimize the flow of materials, products and combination products in a supply chain network structure was fixed (Cohen \& Moon, 1991). Lee and Kim also taking into account resource constraints, the system of production and distribution of multi-plant, multi-product and multi-period presented. Widyarasi and Lashkari provided a hierarchical model that is both strategic and tactical levels. This model is a model plan purchase, production and distribution of that model outputs tactical level model is the strategic level inputs, (Lee, Kim, 2002) Pike and Cohen provided an integrated model of production - distribution of possible that the objective function of production and distribution costs will be minimal and also related to demand and capacity constraints centers. (Patterson. \&, Kim, 2000)

Bilgen (2010) and Liu (2011) and Bravo (2013) in his article concluded that the integration of production and inventory control decisions in the distribution network, created a problem that has recently attracted the attention of many researchers.

In another article by Bustl et al., (2008), a network of multi-step, multi-product production network and distribution network with certain demands were taken into consideration. The purpose of this article is to help decision-makers Adopting strategic and tactical decisions such as opening, closing or expanding facilities, choice of suppliers, and material flow during SC. (Supply chain)

The results Eshraghi Samani et al (2008) showed that the salmon farming industry production technology in the area of non Homothetic and alters the scale of production, the share of the cost of factors of production will change.

Also returns to scale in this industry is growing. Allen substitution elasticity's suggest that the exception had a complementary relationship with labor and food fish, is the relationship between other factors succession.

Nasiri and Karimi (2010) investigated the integration, allocation, and inventory for distribution network design SC's decision. Model as an integer linear programming problem combined to formulate and then use the LR method has been solved.

\section{Research Hypotheses}

1. There is a significant relationship between the inputs in the production process.

2. There is meaningful relationship between the production and average production costs.

3. There is a significant relationship between systematic structure of production and supply chain network structure.

\section{Research Method}

From the perspective of this study is fundamental. In terms of control variables is descriptive - analytical. Issues studied in this research include studies on the structure of production. In terms of territory, the research was conducted in the agricultural sector. In terms of realm of time, time data collection and analysis of survey data from April 2015 will begin. Statistical population was taken in the agricultural sector in the snowball sampling study, 50 experts in the field of agriculture equipment was selected to learn from them. 
Collecting data in this study is a combination of library and field methods. To determine the optimal pattern of production, including the Cobb-Douglas production function common, transcendental, secondarily generalized trans log by software SPSS, eviews5 was estimated and to determine the best function that can explain better structure the Durbin-Watson test for autocorrelation test, variance inflation test for alignment, Jrak test to check for normality and disorder sentences Arch test for heterogeneity of variance was used. According to the description given, following the model as a conceptual model is selected.

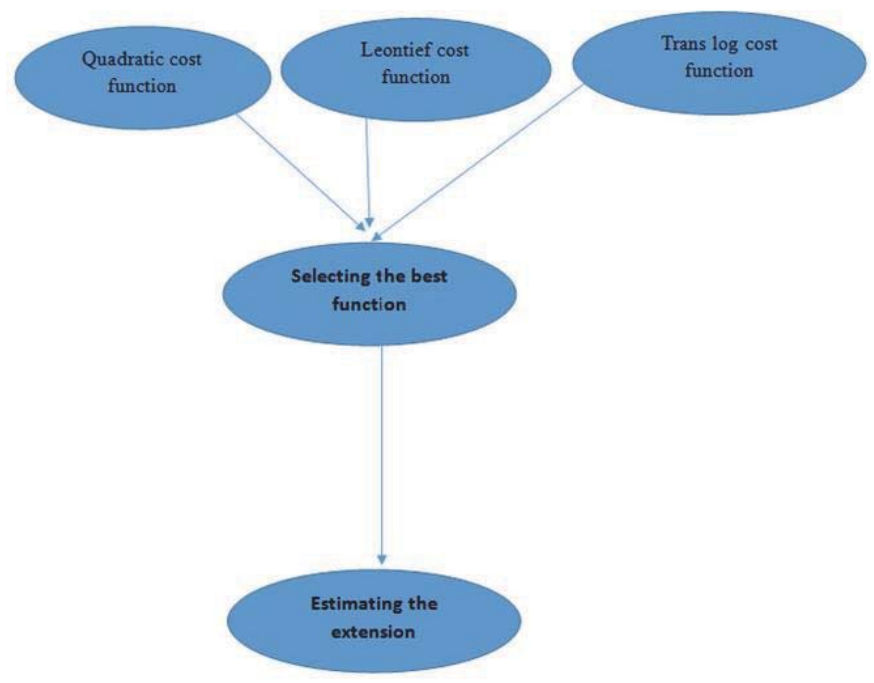

\section{Research Findings}

In this section analysis of econometric software EVIEWS output is examined.

\subsection{Determines the type of function}

Three functions are examined to determine the type of function. The following features have been studied econometrics functions.

A) Generalized Leontief cost function

Consequential form of this function is as follows:

$C=\left[2 \sum_{i=1}^{N} \sum_{j=1}^{N} \gamma_{i j} \sqrt{P_{i} P_{j}}\right]\left[\prod_{k=1}^{K} Q_{k}^{\beta_{i}(P, Q)}\right]$

B) Quadratic cost function

Consequential form of this function is as follows:

$C=\left[\sum_{i=1}^{N} \sum_{j=1}^{N} \gamma_{i j} P P_{i}\right]_{j}^{2}\left[\prod_{k=1}^{K} Q_{k}^{\beta_{i}(P, Q)}\right]$

C) Trans log cost function

Consequential form of this function is as follows:

$$
\ln C=a_{0}+\sum_{i=1}^{N} \alpha_{i} \ln P_{i}+\sum_{i=1}^{N} \sum_{j=1}^{N} \gamma_{i j} \ln P_{i} \ln P_{j}+\sum_{k=1}^{K} \beta_{k} \ln Q_{k}+\sum_{k=1 /=1}^{K} \sum_{2}^{K} \theta_{i k} \ln Q_{k}+\sum_{k=1=1}^{N} \sum_{i=1}^{N} \phi_{i} \ln P_{i} \ln Q_{k}
$$

Assumptions Trans log function is written as follows. 


$$
\sum_{i}^{N} \alpha_{i}=1, \sum_{i} \phi_{q i}=0, \sum_{i}^{N} \gamma_{i j}=\sum_{i}^{N} \gamma_{j i}=\sum_{i}^{N} \sum_{j}^{N} \gamma_{i j}=0
$$

By considering these assumptions, estimates have been made.

In the following table in terms of significant functions and statistical problems have been studied:

Table 1: Comparison of three estimates with each other

\begin{tabular}{|l|c|c|c|l|}
\hline Statistical problem & F-Stat & Coefficient of determination & Significant percent of determination & Estimate \\
\hline Exist & 1.07 & 0.16 & 60 & Leontief cost function \\
\hline Not exist & 933.53 & 0.99 & 50 & Trans log cost function \\
\hline Exist & 251.31 & 0.97 & 0 & Quadratic cost function \\
\hline
\end{tabular}

In the table above the original estimate econometric statistical properties and characteristics described in the third quarter compared with one another. It can be said:

In case of higher $\mathrm{F}$ statistic model is superior.

In case of higher coefficient is determining the best model.

Top model is the most significant percentage of variables.

According to the results table of the Trans log cost function is used. It doesn't have the statistical difficulties.

\subsection{Estimate the total Tran's log cost function}

A) Total cost

Research variables are summarized in the following table:

\begin{tabular}{|c|l|}
\hline SYMBOL & Variable \\
\hline TC & total cost \\
\hline AC & the average cost \\
\hline PWFD & Raw material prices \\
\hline PSAL & Asset price \\
\hline PPOL & Price of labor \\
\hline $\mathbf{Q}$ & Value of product \\
\hline
\end{tabular}

Then, according to the formula outlined in the previous section Trans log total cost function is examined.

Table 2: Trans log total cost function (the dependent variable TC)

\begin{tabular}{|c|c|c|l|}
\hline PROB & T statistic & Coefficient & Variable \\
\hline 0.000 & 5.90 & 16.49 & $\operatorname{Intercept}$ \\
\hline 0.12 & -1.58 & -1.86 & $\operatorname{Ln}(\mathrm{Q})$ \\
\hline & & -0.74 & $\operatorname{Ln}(\mathrm{PPOL})$ \\
\hline 0.000 & 5.95 & 0.15 & $\operatorname{Ln}(\mathrm{PSAL})$ \\
\hline 0.000 & 7.32 & 0.59 & $\operatorname{Ln}(\mathrm{PWFD})$ \\
\hline 0.006 & -2.95 & -0.14 & $\operatorname{Ln}(\mathrm{Q}))^{*}(\operatorname{Ln}(\mathrm{PPOL})$ \\
\hline 0.46 & -0.73 & -0.05 & $\operatorname{Ln}(\mathrm{Q}))^{*}(\operatorname{Ln}(\mathrm{PSAL})$ \\
\hline & & 0.19 & $\operatorname{Ln}(\mathrm{Q}))^{*}(\operatorname{Ln}(\mathrm{PWFD})$ \\
\hline 0.000 & 4.90 & 0.48 & $\operatorname{Ln}(\mathrm{PSAL}))^{* *}(\operatorname{Ln}(\mathrm{PPOL}) 0 / 5$ \\
\hline 0.75 & -0.31 & -0.04 & $\operatorname{Ln}(\mathrm{PWFD}))^{* *}(\operatorname{Ln}(\mathrm{PPOL}) 0 / 5$ \\
\hline & & -0.44 & $\operatorname{Ln}(\mathrm{PSAL}))^{* *}(\operatorname{Ln}(\mathrm{PWF}) 0 / 5$ \\
\hline 0.02 & 2.29 & 0.12 & $\operatorname{Ln}(\mathrm{Q}))^{* *}(\operatorname{Ln}(\mathrm{Q}) 0 / 5$ \\
\hline 0.74 & -0.33 & -0.02 & $\operatorname{Ln}(\mathrm{PPOL}))^{* *}(\operatorname{Ln}(\mathrm{PPOL}) 0 / 5$ \\
\hline 0.84 & -0.19 & -0.01 & $\operatorname{Ln}(\mathrm{PSAL}))^{* *}(\operatorname{Ln}(\mathrm{PSAL}) 0 / 5$ \\
\hline 0.09 & 1.07 & 0.13 & $\operatorname{Ln}(\mathrm{PWFD}))^{* *}(\operatorname{Ln}(\mathrm{PWFD}) 0 / 5$ \\
\hline
\end{tabular}

In the table above Trans log total cost function is evaluated and the function introduced in the third quarter estimate is 
done. Dependent variable was the total cost of manufacturing and operating costs including raw material prices, the price of capital, labor price and quantity of the product as independent variables were entered into the model. Estimate important properties are listed below:

\begin{tabular}{|l|c|l|}
\hline Result & Value & Feature \\
\hline Total cost an adequate explanation by the variable & 0.99 & Coefficient of determination $) R^{2}($ \\
\hline Well fitted to estimate & 560.35 & F statistic )F-STAT( \\
\hline The absence of autocorrelation in waste & 1.97 & Durbin- Watson \\
\cline { 1 - 3 }
\end{tabular}

To ensure the estimation of variance heterogeneity test is given below. White test given that the time series model is losing its applicability and instead test Glechser test was conducted.

Table 3: ANOVA heterogeneity (Glechser)

\begin{tabular}{|l|c|c|c|}
\hline Result & Significance & Freedom degree & Obtained statistic \\
\hline Heterogeneity was not confirmed & 0.24 & $(14$ and 30$)$ & 1.33 \\
\hline
\end{tabular}

\subsection{Analysis of tension and return to scale}

Stretching can be calculated from the following formula:

$$
E_{C}=\frac{\partial \ln (C)}{\partial \ln (Q)}=\frac{\partial C}{\partial Q} \times \frac{Q}{C}=\frac{M C}{A C}
$$

With calculations were performed to estimate the elasticity of the cost of 0.95 is obtained which is a number greater than one and represents the increase in the average cost of a production unit 0.95 is incremented. A total of Agriculture studied the economies of scale as well as 1.05 returns to scale is an increase of the output scale.

In the survey reveals that $56 \%$ of individual units have increasing returns to scale and decreasing returns to scale are $44 \%$ of the units.

B) The average cost

Then estimate the Trans log function using the average cost is provided.

Table 4: Average trans log cost function (the dependent variable AC)

\begin{tabular}{|c|c|c|l|}
\hline PROB & T statistic & Coefficient & Variable \\
\hline 0.000 & 5.90 & 16.49 & Intercept \\
\hline 0.02 & -2.44 & -2.86 & $\operatorname{Ln}(\mathrm{Q})$ \\
\hline & & -0.74 & $\operatorname{Ln}(\mathrm{PPOL})$ \\
\hline 0.000 & 5.95 & 0.15 & $\operatorname{Ln}(\mathrm{PSAL})$ \\
\hline 0.000 & 7.32 & 0.59 & $\operatorname{Ln}(\mathrm{PWFD})$ \\
\hline 0.006 & -2.95 & -0.14 & $\operatorname{Ln}(\mathrm{Q}))^{*}(\operatorname{Ln}(\mathrm{PPOL})$ \\
\hline 0.46 & -0.73 & -0.05 & $\operatorname{Ln}(\mathrm{Q}))^{*}(\operatorname{Ln}(\mathrm{PSAL})$ \\
\hline & & 0.19 & $\operatorname{Ln}(\mathrm{Q}))^{*}(\operatorname{Ln}(\mathrm{PWFD})$ \\
\hline 0.000 & 4.90 & 0.48 & $\operatorname{Ln}(\mathrm{PSAL}))^{* *}(\operatorname{Ln}(\mathrm{PPOL}) 0 / 5$ \\
\hline 0.75 & -0.31 & -0.04 & $\operatorname{Ln}(\mathrm{PWFD}))^{* *}(\operatorname{Ln}(\mathrm{PPOL}) 0 / 5$ \\
\hline & & -0.44 & $\operatorname{Ln}(\mathrm{PSAL}))^{* *}(\operatorname{Ln}(\mathrm{PWFD}) 0 / 5$ \\
\hline 0.02 & 2.29 & 0.12 & $\operatorname{Ln}(\mathrm{Q}))^{* *}(\operatorname{Ln}(\mathrm{Q}) 0 / 5$ \\
\hline 0.74 & -0.33 & -0.02 & $\operatorname{Ln}(\mathrm{PPOL}))^{* *}(\operatorname{Ln}(\mathrm{PPOL}) 0 / 5$ \\
\hline 0.84 & -0.19 & -0.01 & $\operatorname{Ln}(\mathrm{PSAL}))^{* *}(\operatorname{Ln}(\mathrm{PSAL}) 0 / 5$ \\
\hline 0.09 & 1.07 & 0.13 & $\operatorname{Ln}(\mathrm{PWFD}))^{* *}(\operatorname{Ln}(\mathrm{PWF}) 0 / 5$ \\
\hline
\end{tabular}

According to findings the above table, the dependent variable was the average cost of production and production costs, including raw material prices, the price of capital, labor price and quantity of the product as independent variables were entered into the model.

Estimate important properties are listed below: 


\begin{tabular}{|l|c|l|}
\hline Result & Value & Feature \\
\hline Sufficient explanation of total cost by variables & 0.99 & Coefficient of determination $) \mathrm{R}^{2}($ \\
\hline Fitted estimation & 220.88 & F statistic $)$ F-STAT( \\
\hline Lack of self-correlation in waste & 1.97 & Durbin-Watson \\
\hline
\end{tabular}

White test given that the time series model is losing its applicability and instead test Golchser test was conducted.

Table 3: ANOVA heterogeneity (Golchser)

\begin{tabular}{|l|c|c|c|}
\hline Result & Significance & Freedom degree & Obtained statistic \\
\hline Heterogeneity is not confirmed & 0.24 & $(14$ and 30$)$ & 1.33 \\
\hline
\end{tabular}

\section{4 generalized Leontief function}

A) Total cost

Then, according to the formula outlined in the previous section, the Leontief generalized cost function is examined.

Table 6: Total Leontief generalized cost function (the dependent variable TC)

\begin{tabular}{|c|c|c|c|}
\hline PROB & T statistic & Coefficient & Variable \\
\hline 1.00 & $5.28^{*} \mathrm{e}^{-10}$ & 7.27 & Intercept \\
\hline 0.03 & 2.22 & $6.08^{*} \mathrm{e}^{-9}$ & PPOL*PPOL \\
\hline 0.07 & -1.81 & $-1.81^{*} \mathrm{e}^{-8}$ & PPOL*PSAL \\
\hline 0.04 & -2.07 & $-1.01^{*} \mathrm{e}^{-9}$ & PPOL*PWFD \\
\hline 0.48 & 0.70 & $3.39^{*} \mathrm{e}^{-10}$ & PSAL*PSAL \\
\hline 0.09 & 1.69 & $2.74^{*} \mathrm{e}^{-9}$ & PWFD*PSAL \\
\hline 0.01 & 2.51 & $2.12^{*} \mathrm{e}^{-11}$ & PWFD*PWFD \\
\hline 1.00 & $1.27^{*} \mathrm{e}^{-8}$ & 0.28 & Q \\
\hline
\end{tabular}

According to findings the above table, the dependent variable is the total cost of manufacturing and operating costs including raw material prices, the price of capital, labor price and quantity of the product as independent variables were entered into the model.

Estimate important properties are listed below:

\begin{tabular}{|l|c|l|}
\hline Result & Value & Feature \\
\hline Sufficient explanation of total cost by variables & 0.48 & Coefficient of determination $) \mathrm{R}^{2}($ \\
\hline Fitted estimation & 5.02 & F statistic )F-STAT( \\
\hline Lack of self-correlation in waste & 0.75 & Durbin-Watson \\
\hline
\end{tabular}

B) Average cost

Table 7: Average Leontief generalized cost function (the dependent variable TC)

\begin{tabular}{|c|c|c|c|}
\hline PROB & T statistic & Coefficient & Variable \\
\hline 1.00 & $5.28^{*} \mathrm{e}^{-10}$ & 7.27 & Intercept \\
\hline 0.03 & 2.22 & $1.16^{*} \mathrm{e}^{-18}$ & PPOL ${ }^{*} \mathrm{PPOL}$ \\
\hline 0.07 & -1.81 & $-2.78^{*} \mathrm{e}^{-17}$ & PPOL ${ }^{*} \mathrm{PSAL}$ \\
\hline 0.04 & -2.07 & $-4.49^{*} \mathrm{e}^{-17}$ & PPOL*PWFD \\
\hline 0.48 & 3.02 & $1.54^{*} \mathrm{e}^{-17}$ & PSAL*PSAL \\
\hline 0.09 & 0.53 & $7.24^{*} \mathrm{e}^{-16}$ & PWFD*PSAL \\
\hline 0.01 & 2.008 & $9.27^{*} \mathrm{e}^{-16}$ & PWFD*PWFD \\
\hline 0.003 & 3.08 & $0 / 13$ & Q \\
\hline
\end{tabular}

According to findings the above table, the dependent variable was the average cost of production and production costs, including raw material prices, the price of capital, labor price and quantity of the product as independent variables were 
entered into the model.

Estimate important properties are listed below:

\begin{tabular}{|l|c|l|}
\hline Result & Value & Feature \\
\hline Insufficient explanation of total cost by variables & 0.16 & Coefficient of determination )R2( \\
\hline Not Fitted estimation & 1.07 & F statistic )F-STAT( \\
\hline Self-correlation in waste & 1.20 & Durbin-Watson \\
\hline
\end{tabular}

\subsection{Assumptions}

Assumptions of this thesis are studied using t-test. If we compare two samples, following methods are used. T test is used to compare the means.

\subsubsection{Evaluate the first hypotheses}

H0: There is no significant relationship between the inputs in the production process.

$\mathrm{H} 1$ : There is a significant relationship between the inputs in the production process.

In the following table summarizes the results of the study hypothesis with the t-test:

Table 8: Results of the survey the first hypothesis

\begin{tabular}{|l|c|c|c|}
\hline Result & Significant level & Freedom degree & T statistic \\
\hline Rejecting zero hypothesis & 0.02 & 44 & 2.18 \\
\hline
\end{tabular}

It is enough to reject the null hypothesis, the significance level is less than 0.05 , and here there is a significant level of 0.02 that therefore the null hypothesis is rejected. Therefore, there is a significant relationship between the inputs in the production process.

\subsubsection{Evaluate the second hypotheses}

$\mathrm{HO}$ : there is no significant relationship between the average costs of production and production.

$\mathrm{H} 1$ : There is meaningful relationship between the production and average production costs.

In the following table summarizes the results of the study hypothesis with the t-test:

Table 9: Results of the survey the second hypothesis

\begin{tabular}{|l|c|c|c|}
\hline Result & Significant level & Freedom degree & T statistic \\
\hline Zero hypothesis is rejected & 0.01 & 44 & 2.37 \\
\hline
\end{tabular}

It is enough to reject the null hypothesis significance level of less than 0.05 ; here there is a significant level of 0.01 that therefore the null hypothesis is rejected. So, there is meaningful relationship between the production and average production costs.

\subsection{3 evaluate third the hypotheses}

HO: There is no significant relationship between the systematic structure of production and supply chain network structure.

$\mathrm{H} 1$ : There is a significant relationship between the systematic structure of production and supply chain network structure.

In the following table summarizes the results of the study hypothesis with the t-test:

Table 10: Results of the survey the third hypothesis

\begin{tabular}{|l|c|c|c|}
\hline Result & Significant level & Freedom degree & T statistic \\
\hline Zero hypothesis is rejected & 0.005 & 44 & 2.85 \\
\hline
\end{tabular}


It is enough to reject the null hypothesis significance level of less than 0.05 ; here there is a significant level of 0.005 that therefore the null hypothesis is rejected. Therefore, between the systematic structure of production and supply chain network structure there is a significant relationship.

According to analysis carried out in the assumptions continue thesis is summarized in table form.

Table 11: The results of assumptions thesis

\begin{tabular}{|l|l|c|}
\hline Result & Hypothesis & Row \\
\hline Approved & There is a significant relationship between the inputs in the production process. & 1 \\
\hline Approved & There is meaningful relationship between the production and average production costs. & 2 \\
\hline Approved & There is a significant relationship between the systematic structure of production and supply chain network structure & 3 \\
\hline
\end{tabular}

According to calculations in the calculation of the cost of agricultural unit, it can be said Trans log cost function with a unit cost of agricultural functions in the sample matches and this function can be used to calculate the costs and traction. Also following results have been obtained from the study assumptions:

* There is a significant relationship between the inputs in the production process.

* There is meaningful relationship between the production and average production costs.

* There is a significant relationship between the systematic structure of production and supply chain network structure.

\section{Conclusions}

\subsection{Findings obtained hypothesis tests with comparable results are as follows;}

Imanipour in 2004 investigated the integration process planning and scheduling in flexible manufacturing system and modeling study conducted workshops with multiple objective functions. In this issue, the planning process has two levels of flexibility in sequence and track. Timing objectives include: minimization "The maximum duration of parts, components and maximum average time was early / late" that with philosophy of timely and consistent supply chain management objectives and expected control them simultaneously to improve system performance.

Based on the results Eshraghi Samani et al. (2008), production technology salmon farming industry in the area of non homothetic and alters the scale of production, the share of the cost of factors of production will change. Saving labor and capital saving technology and production cost of food inputs and fry in effect of increasing the scale of production increases. Also returns to scale in this industry is growing. Allen substitution elasticity's suggest that the exception had a complementary relationship with labor and food fish, is the relationship between other factors succession.

Stretch computing Biggs et al (2006) Showed that Canadian logging industry substitution capital for labor is much easier than replacing labor rather than capital, which represents user technology in the industry. In the elasticity's study, Kavvy and colleagues (2009) indicate that there is widespread substitution of inputs, including a succession of food grain with a protein food. Results showed no economies of scale in the production of milk in Kenya.

Vakharya and colleagues (1999) summarized research in the field of production and distribution in the supply chain. Check the like capacity, lead time sensitive timing and uncertainty in the wider supply chain, the development of an integrated approach to minimize inventory at all stages of the supply chain, the effect of encouraging the sharing of information in the supply chain and supply chain partners to share information and finally, mathematical models and simulations that can be seamlessly connected to the three main parts of the supply chain, as important areas for future research are presented in the supply chain.

As you can see, according to research and compare it with this research, it was found that with cost structure of production function approach to assess the scale of production and cost of production factors can be changed and also can be said that between the production and average production costs and between the systematic structure of production and supply chain network structure there is a significant relationship that utilizes the results can be achieved economies of scale and to increase market share and profits for all organizations involved in the supply chain can be achieved.

\section{References}

Eshraghi Samani, R, Yazdani, S, Sadrosharafi, M Peikani GH, 2008, the structure of the salmon farming industry in Chaharmahal and 
Bakhtiari Province, modern agricultural science magazine Issue 10, Pages 1-15.

Imani Pour, Narges (2004) "integrated process planning and scheduling in flexible manufacturing plant with multiple objective functions", $\mathrm{PhD}$ thesis, University Lecturer, Faculty of Engineering,

Ghazanfari Mahdi, Riazi, Afshin; Kazemi, Masoud (1380) General Supply Chain Management, Magazine: plan, No. 117, pp 20-27

Dashti, GH, Shorafa, S, 2009, analysis of the economic efficiency of scale and optimal size of breeding hens in Tehran, Agriculture and Development, Issue 68

Vakharia Asoo J. , Erenguc S. , Simpson N.C. , 1999 ,Integrated production/distribution planning in supply chains: An invited review, European Journal of Operational Research 115, 219-236

Kavoi MM, Hoag D and Pritchett J, 2009. Production structure and derived demand for factor inputs in smallholder dairying Kenya. AFJARE 32: 122-143.

Patterson, L.J., Kim, M., Strategic sourcing: a systematic approach to supplier evaluation, selection and development, Caps research, Vol. 4, pp:125-112, .2000

Pirkul and V. Jayaraman. A multi-commodity, multi-plant, capacitated facility location problem: formulation and e_cient heuristic solution. Computers and Operations Research, 25(10):869\{878, 1998.

Cohen. A, Morris and Sangwon Moon (1991) "An integrated plant loading model with economice of scale and scope", European Journal Of Operation Research, No. 50, pp. 266-276.

Lee.Y.H, Kim .S.H, (2002) "Production-distribution planning in supply chain considering capacity constraints", computer and industrial engineering, Vol. 43, pp. 169-190.

Thanh, P. N., Bostel, N., \& Peton, O. (2008). A dynamic model for facility location in the design of complex supply chains. International Journal of Production Economics, 113(2), 678-693.

Nasiri, G. R., Davoudpour, H., \& Karimi, B. (2010a). The impact of integrated analysis on supply chain management: A coordinated approach for inventory control policy. Supply Chain Management: An International Journal, 15(4), 277-289

Biggs, J\& Birenbaum, M.. (2006). Enhancing learning: A matter of style or approach? In R.J. Sternberg \& L.F. Zhang (Eds.), Perspectives on thinking, learning, and cognitive styles (pp. 73-102). Mahwah, NJ: Lawrence Erlbaum Associates, Publishers. 